\title{
Lithium Benzoate
}

National Cancer Institute

\section{Source}

National Cancer Institute. Lithium Benzoate. NCI Thesaurus. Code C76050.

The lithium salt form of benzoic acid with diuretic and urinary antiseptic activity. Lithium benzoate exerts natriuretic activity and disinfects the urinary tract, but has considerable toxicity. 